\title{
Implementations of Dijkstra Algorithm for Searching the Shortest Route of Ojek Online and a Fuzzy Inference System for Setting the Fare Based on Distance and Difficulty of Terrain (Case Study: in Semarang City, Indonesia)
}

\author{
Vani Natali Christie Sebayang, Isnaini Rosyida*
}

\author{
Universitas Negeri Semarang, Indonesia \\ *Corresponding author: Email: isnaini@mail.unnes.ac.id
}

\begin{abstract}
Ojek Online is a motorcycle taxi that is usually used by people that need a short time for traveling. It is one of the easiest forms of transportation, but there are some obstacles in hilly areas such as Semarang City. The fare produced by online motorcycle taxis is sometimes not in accordance with the distance and difficulty of the terrain. The problems in this research are as follows: (1) How to find the shortest route of Ojek Online using the Dijkstra Algorithm, (2) How are the difficulties of the terrain along the shortest routes, (3) How to determine the fare using a fuzzy inference system (FIS) where the inputs are distance and the level of difficulty of the terrain on the geographical map in Semarang City area. The Dijkstra's Algorithm is used to assist in finding the shortest path and the Mamdani FIS is applied for fixing the fares. The results show that the Dijkstra Algorithm can find the shortest routes of ojek online from UNNES (initial node) to some destinantions in Semarang City. The result using fuzzy logic toolbox in matlab with the input of distance 5.5 $\mathrm{km}$ and terrain difficulty $300 \mathrm{~m}$ produced an output fare of 13,500 IDR. Further, the input of distance $5.5 \mathrm{~km}$ and the terrain difficulty of 100 m poduced an output fare of 13,100 IDR. Some routes with the same distance and different terrain heights have different fares.
\end{abstract}

Keywords: Dijkstra algorithm, Fuzzy Inference System (FIS), Shortest route, Fare, Distance, Terrain difficulty.

\section{INTRODUCTION}

Transportation is a tool used to move from one place to another. Some human activities are closely related to transportation, where humans need it to move from one place to another more easily. The development of increasingly advanced technology makes various new innovations in the world of transportation appear, one of which is online motorcycle taxis or we called as "Ojek Online" (in Indonesia). It is one of the transportations that is easy to get and is an alternative for people during peak time, so they need fast and time-saving transportation. However, there are several obstacles that must be faced between Ojek Online users and drivers, one of which is the rates generated by Ojek Online system sometimes is not appropriate with the distance and difficulty of the terrain that must be taken. Online Ojek drivers sometimes have difficulty when they they pass through alternative roads with difficult terrain, such as a fairly steep incline in hilly areas in Semarang City, but the total cost does not match with the real condition.

Therefore, this study examines: (1) How to search the shortest path of Ojek Online using Dijkstra's Algorithm, (2) How to find the terrain difficulty in the area traversed along the shortest path, (3) How are the fares based on the Mamdani fuzzy inference system (FIS) with the input the distance and difficulty level of the terrain on the geographical map in the Semarang City area.

\section{RELATED WORKS}

A graph $G=(V, E)$ consists of a vertex set $V$ (nonempty) and an edge set $E$ (might be empty). The set $E$ is a subset of $V \times V$. A graph is divided into two types, namely undirected graphs and directed graphs based on the orientation in the edges [1]. Dijkstra's algorithm is an algorithm used to determine the shortest distance from one vertex to another in a weighted graph, the distance 
between vertices is the weight value of each edge in the graph where a weight must be positive. Dijkstra's algorithm was invented by Edger Wybe Dijkstra. It is also known as the greedy algorithm, which is an algorithm that solves problems by finding the maximum value. The Dijkstra's algorithm performs in searching the shortest path through the calculation from the original vertex to the nearest vertex, then to the second vertex, and so on [2]. A fast and reliable Dijkstra Algorithm for online shortest path was investigated by [3] where the shortest path was applied to send emergency vehicles such as ambulances, fire fighting vehicles and others. Further, the result on the implementation of Dijkstra's Algorithm in finding the nearest distance from user locations to destined plants based on android (Case Study at Purwodadi Botanical Gardens) was proposed by [4]. In [5], the authors investigated the problem of finding of nearest gas stations and determining the shortest distance using Dijkstra's Algorithm. A study of design and implementation of a framework to find nearest hotels and booking systems in Iraqi was provided in [6]. Compared to other algorithms such as Floyd-Warshall Algorithm, Dijkstra's Algorithm has more advantages and one of the advantages is the less time and storage in using it [7].

A Mamdani Fuzzy Inference System (FIS) is also known as the Max-Min method in FIS. This method was introduced by Ebrahim Mamdani in 1975. A research on Intelligent Transportation System (ITS) for Smart Cities using Mamdani FIS has been conducted by [8]. They used the Mamdani FIS to solve traffic congestion problems based on rule based. Furthermore, the use of Mamdani FIS to support decisions on determining village potential in Malang district was done by [9]. Mamdani FIS is able to describe expert expertise more intuitively, which is more like an expert in making decisions [10]. Furthermore, a combination between fuzzy chromatic number and Mamdani FIS was constructed for fuzzy traffic light phase assignment and phase timings [11].

\section{METHODS}

Determination of the shortest path begins by giving the status of the point that has not been selected initialized with " 0 " and the one that has been selected is initialized with " 1 " starting from the starting point, then determining the weight of the point that is directly related to the starting point and the point that has no path (arc) that connects directly to the starting point is given the initial "-", then the Predecessor is the source point of the other points that connect each other, while for the point that there is no direct path connecting from the source point, so that the distance does not exist, it is initialized with "". If all points have been selected then the program will stop so that it can find out the shortest path selected from the starting point to every other point. As for the steps in Dijkstra's Algorithm, it is known that the weight graph is:

1. label the point with and for each point in addition to, label the point with

2. let's say with minimum
3. if STOP, and give a message the length of the shortest path from to is

4. for each side; replace label with

5. write and return to step 2 [12]

Determination of the fares based on distance and terrain difficulty using the Mamdani FIS, four stages are needed, namely the formation of fuzzy sets, construction of fuzzy implications (rules), composition of rules and defuzzification [13]. An example of the implementation of the Mamdani FIS is the application of fuzzy logic in optimizing palm oil production at PT. Waru Kaltim Plantation uses the mamdani method [14].

The procedures used in this research is summarized in Figure 1.

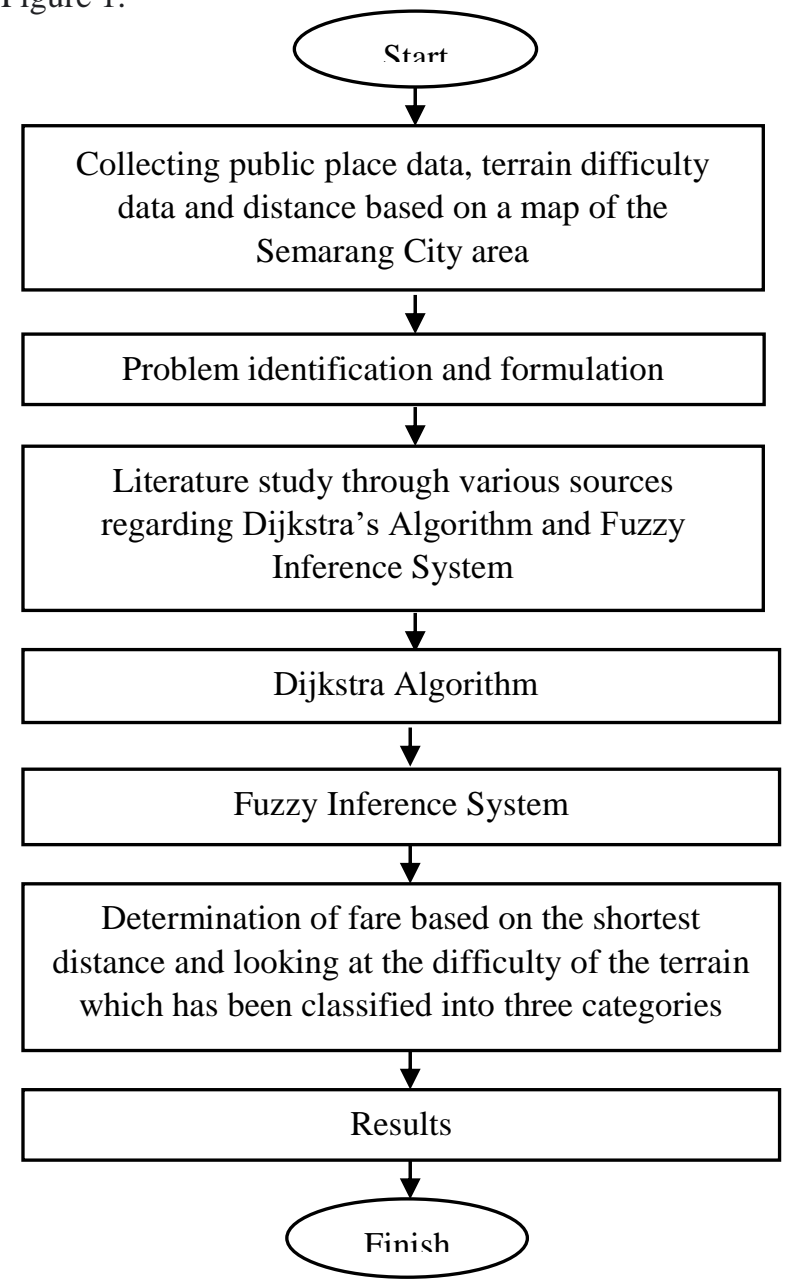

Figure 1. The stages used in this research.

\section{RESULTS AND DISCUSSIONS}

The data of public places and intersections in Semarang City are presented in Table 1 . We describe vertices as public places and intersections and the edges represent the connecting road between two places. Meanwhile, the weights on each edge represent the distance between the two places. The data of edges and the weights are shown in Table 2. 
Table 1. Data of Public Places in Semarang City

\begin{tabular}{|c|c|}
\hline Vertex $v_{i}$ & Description \\
\hline$v_{1}$ & SemarangState University \\
\hline$v_{2}$ & DP Mall Semarang \\
\hline$v_{3}$ & Poncol Station \\
\hline$v_{4}$ & Paragon City Mall \\
\hline$v_{5}$ & Johar Market \\
\hline$v_{6}$ & Ada Supermarket \\
\hline$v_{7}$ & Lawang Sewu \\
\hline$v_{8}$ & Semawis Pecinan \\
\hline$v_{9}$ & Diponegoro University \\
\hline$v_{10}$ & Indonesia Kaya Park \\
\hline$v_{11}$ & Semarang Tawang Station \\
\hline$v_{12}$ & Javamall Semarang \\
\hline$v_{13}$ & Pancasila Simpang 5 Field \\
\hline$v_{14}$ & Agung Jawa Tengah Mosque \\
\hline$v_{15}$ & Sampangan Market \\
\hline$v_{16}$ & Kerempyang Traditional Market \\
\hline$v_{17}$ & Dr. Kariadi Hospital \\
\hline$v_{18}$ & Goa Kreo \\
\hline$v_{19}$ & Sukun Bus Station \\
\hline$v_{20}$ & Terboyo Bus Station \\
\hline$v_{21}$ & Kota Lama \\
\hline$v_{22}$ & Cross Road \\
\hline$v_{23}$ & Cross Road \\
\hline$v_{24}$ & Cross Road \\
\hline$v_{25}$ & Cross Road \\
\hline$v_{26}$ & Cross Road \\
\hline$v_{27}$ & Cross Road \\
\hline$v_{28}$ & Cross Road \\
\hline$v_{29}$ & Cross Road \\
\hline$v_{30}$ & Cross Road \\
\hline$v_{31}$ & Cross Road \\
\hline$v_{32}$ & Cross Road \\
\hline$v_{33}$ & Cross Road \\
\hline$v_{34}$ & Cross Road \\
\hline$v_{35}$ & Cross Road \\
\hline$v_{36}$ & Cross Road \\
\hline$v_{37}$ & Cross Road \\
\hline$v_{38}$ & Cross Road \\
\hline$v_{39}$ & Cross Road \\
\hline$v_{40}$ & Cross Road \\
\hline$v_{41}$ & Cross Road \\
\hline$v_{42}$ & Cross Road \\
\hline$v_{43}$ & Cross Road \\
\hline$v_{44}$ & Cross Road \\
\hline$v_{45}$ & Cross Road \\
\hline$v_{46}$ & Cross Road \\
\hline
\end{tabular}

Table 2. The Data of Edges and Distance between Two Places

\begin{tabular}{|c|c|}
\hline Edge & Weight (Km) \\
\hline$x_{1}: v_{1}-v_{18}$ & 12 \\
\hline$x_{2}: v_{1}-v_{26}$ & 3.7 \\
\hline$x_{3}: v_{6}-v_{19}$ & 0.8 \\
\hline$x_{4}: v_{19}-v_{9}$ & 3 \\
\hline$x_{5}: v_{9}-v_{27}$ & 2.4 \\
\hline$x_{6}: v_{27}-v_{24}$ & 2.2 \\
\hline$x_{7}: v_{24}-v_{28}$ & 0.8 \\
\hline$x_{8}: v_{28}-v_{12}$ & 3.1 \\
\hline$x_{9}: v_{12}-v_{37}$ & 0.7 \\
\hline$x_{10}: v_{37}-v_{42}$ & 1.2 \\
\hline$x_{11}: v_{42}-v_{43}$ & 0.95 \\
\hline$x_{12}: v_{43}-v_{14}$ & 2.5 \\
\hline$x_{13}: v_{14}-v_{20}$ & 6.6 \\
\hline$x_{14}: v_{43}-v_{8}$ & 2.4 \\
\hline$x_{15}: v_{8}-v_{5}$ & 1.2 \\
\hline$x_{16}: v_{5}-v_{21}$ & 0.75 \\
\hline$x_{17}: v_{21}-v_{11}$ & 0.5 \\
\hline$x_{18}: v_{46}-v_{5}$ & 0.9 \\
\hline$x_{19}: v_{11}-v_{20}$ & 5.1 \\
\hline$x_{20}: v_{46}-v_{11}$ & 0.9 \\
\hline$x_{21}: v_{46}-v_{3}$ & 1 \\
\hline$x_{22}: v_{45}-v_{3}$ & 0.9 \\
\hline$x_{23}: v_{45}-v_{4}$ & 0.8 \\
\hline$x_{24}: v_{4}-v_{2}$ & 0.75 \\
\hline$x_{25}: v_{2}-v_{7}$ & 0.24 \\
\hline$x_{26}: v_{7}-v_{17}$ & 1.2 \\
\hline$x_{27}: v_{17}-v_{34}$ & 0.4 \\
\hline$x_{28}: v_{39}-v_{10}$ & 1.6 \\
\hline$x_{29}: v_{13}-v_{10}$ & 1.3 \\
\hline$x_{30}: v_{42}-v_{13}$ & 1.8 \\
\hline$x_{31}: v_{33}-v_{37}$ & 2.4 \\
\hline$x_{32}: v_{30}-v_{33}$ & 0.22 \\
\hline$x_{33}: v_{29}-v_{30}$ & 0.3 \\
\hline$x_{34}: v_{28}-v_{29}$ & 2 \\
\hline$x_{35}: v_{25}-v_{24}$ & 3.6 \\
\hline$x_{36}: v_{1}-v_{16}$ & 0.35 \\
\hline$x_{37}: v_{16}-v_{22}$ & 3.7 \\
\hline$x_{38}: v_{18}-v_{22}$ & 6.6 \\
\hline$x_{39}: v_{22}-v_{25}$ & 0.17 \\
\hline$x_{40}: v_{25}-v_{23}$ & 0.21 \\
\hline$x_{41}: v_{35}-v_{23}$ & 4 \\
\hline$x_{42}: v_{23}-v_{15}$ & 0.03 \\
\hline$x_{43}: v_{15}-v_{31}$ & 1.5 \\
\hline$x_{44}: v_{29}-v_{31}$ & 2.8 \\
\hline$x_{45}: v_{30}-v_{34}$ & 2.2 \\
\hline$x_{46}: v_{33}-v_{38}$ & 1.8 \\
\hline
\end{tabular}


The graph model of the network of public places and the connecting roads between placesare described in Figure 2.

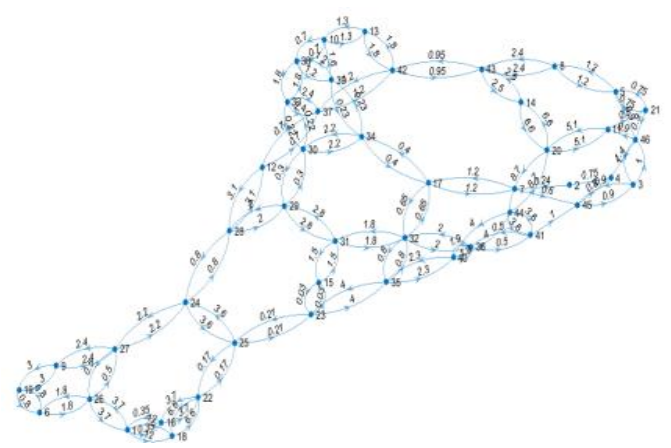

Figure 2. The Graph model of network of Public Places in Semarang City

The process of Dijkstra Algorithm for searching shortest paths from Semarang State University to public places in Semarang City is presented in Table 3.

Table 3. Iteration Results

\begin{tabular}{|c|c|c|c|c|c|c|}
\hline Vertex & $v_{1}$ & $v_{2}$ & $v_{3}$ & $v_{4}$ & $v_{5}$ & $v_{6}$ \\
\hline Status & 1 & 1 & 1 & 1 & 1 & 1 \\
\hline Weight & 0 & 11.76 & 11.11 & 11.01 & 13.01 & 5.5 \\
\hline Source & $v_{1}$ & $v_{4}$ & $v_{45}$ & $v_{45}$ & $v_{46}$ & $v_{26}$ \\
\hline Vertex & $v_{7}$ & $v_{8}$ & $v_{9}$ & $v_{10}$ & $v_{11}$ & $v_{12}$ \\
\hline Status & 1 & 1 & 1 & 1 & 1 & 1 \\
\hline Weight & 9.61 & 14.21 & 6.1 & 10.64 & 13.01 & 10.3 \\
\hline Source & $v_{17}$ & $v_{5}$ & $v_{27}$ & $v_{39}$ & $v_{46}$ & $v_{28}$ \\
\hline Vertex & $v_{13}$ & $v_{14}$ & $v_{15}$ & $v_{16}$ & $v_{17}$ & $v_{18}$ \\
\hline Status & 1 & 1 & 1 & 1 & 1 & 1 \\
\hline Weight & 11.94 & 15.65 & 4.46 & 0.35 & 8.41 & 10.65 \\
\hline Source & $v_{10}$ & $v_{43}$ & $v_{23}$ & $v_{1}$ & $v_{32}$ & $v_{22}$ \\
\hline Vertex & $v_{19}$ & $v_{20}$ & $v_{21}$ & $v_{22}$ & $v_{23}$ & $v_{24}$ \\
\hline Status & 1 & 1 & 1 & 1 & 1 & 1 \\
\hline Weight & 6.3 & 18.11 & 13.51 & 4.05 & 4.43 & 6.4 \\
\hline Source & $v_{6}$ & $v_{11}$ & $v_{11}$ & $v_{16}$ & $v_{25}$ & $v_{27}$ \\
\hline Vertex & $v_{25}$ & $v_{26}$ & $v_{27}$ & $v_{28}$ & $v_{29}$ & $v_{30}$ \\
\hline Status & 1 & 1 & 1 & 1 & 1 & 1 \\
\hline Weight & 4.22 & 3.7 & 4.2 & 7.2 & 8.76 & 9.06 \\
\hline Source & $v_{22}$ & $v_{1}$ & $v_{26}$ & $v_{24}$ & $v_{31}$ & $v_{29}$ \\
\hline Vertex & $v_{31}$ & $v_{32}$ & $v_{33}$ & $v_{34}$ & $v_{35}$ & $v_{36}$ \\
\hline Status & 1 & 1 & 1 & 1 & 1 & 1 \\
\hline Weight & 5.96 & 7.76 & 9.28 & 8.81 & 8.43 & 9.76 \\
\hline Source & $v_{15}$ & $v_{31}$ & $v_{30}$ & $v_{17}$ & $v_{32}$ & $v_{32}$ \\
\hline Vertex & $v_{37}$ & $v_{38}$ & $v_{39}$ & $v_{40}$ & $v_{41}$ & $v_{42}$ \\
\hline Status & 1 & 1 & 1 & 1 & 1 & 1 \\
\hline Weight & 11 & 10.24 & 9.04 & 10.73 & 10.26 & 12.2 \\
\hline Source & $v_{12}$ & $v_{39}$ & $v_{34}$ & $v_{35}$ & $v_{36}$ & $v_{37}$ \\
\hline Status & & & 1 & 1 & 1 & 1 \\
\hline Weight & & & 13.15 & 13.86 & 10.21 & 12.11 \\
\hline & & $v_{42}$ & $v_{41}$ & $v_{7}$ & $v_{3}$ \\
\hline & & & & \\
\hline & & & $v_{37}$ & $v_{38}$ & $v_{39}$ & $v_{40}$ \\
\hline Source & & & & & & \\
\hline
\end{tabular}

There are some places that have a different return directions. The iteration results of Dijkstra's Algorithm, the distance from Semarang State University to several public places in Semarang City, and the distance of the return directions are as follows.

Table 4. The shortest distance Resulted by Dijkstra's Algorithm

\begin{tabular}{|c|c|}
\hline Source and Detination Vertices & Distance \\
\hline$v_{1}$ to $v_{2}$ & 11.7 \\
\hline$v_{2}$ to $v_{1}$ & 9.85 \\
\hline$v_{1}$ to $v_{3}$ & 11.11 \\
\hline$v_{3}$ to $v_{1}$ & 12.3 \\
\hline$v_{1}$ to $v_{4}$ & 11.01 \\
\hline$v_{4}$ to $v_{1}$ & 10.6 \\
\hline$v_{1}$ to $v_{5}$ & 13.01 \\
\hline$v_{5}$ to $v_{1}$ & 12.9 \\
\hline$v_{1}$ to $v_{6}$ & 5.5 \\
\hline$v_{6}$ to $v_{1}$ & 5.5 \\
\hline$v_{1}$ to $v_{7}$ & 9.61 \\
\hline$v_{7}$ to $v_{1}$ & 9.61 \\
\hline$v_{1}$ to $v_{8}$ & 14.21 \\
\hline$v_{8}$ to $v_{1}$ & 14.1 \\
\hline$v_{1}$ to $v_{9}$ & 6.6 \\
\hline$v_{9}$ to $v_{1}$ & 6.6 \\
\hline$v_{1}$ to $v_{10}$ & 10.64 \\
\hline$v_{10}$ to $v_{1}$ & 10.94 \\
\hline$v_{1}$ to $v_{11}$ & 13.01 \\
\hline$v_{11}$ to $v_{1}$ & 13.4 \\
\hline$v_{1}$ to $v_{12}$ & 10.3 \\
\hline$v_{12}$ to $v_{1}$ & 10.3 \\
\hline$v_{1}$ to $v_{13}$ & 11.94 \\
\hline$v_{13}$ to $v_{1}$ & 12.24 \\
\hline$v_{1}$ to $v_{14}$ & 15.65 \\
\hline$v_{14}$ to $v_{1}$ & 15.65 \\
\hline$v_{1}$ to $v_{15}$ & 4.46 \\
\hline$v_{15}$ to $v_{1}$ & 4.46 \\
\hline$v_{1}$ to $v_{16}$ & 0.35 \\
\hline$v_{16}$ to $v_{1}$ & 0.35 \\
\hline$v_{1}$ to $v_{17}$ & 8.41 \\
\hline$v_{17}$ to $v_{1}$ & 8.41 \\
\hline$v_{1}$ to $v_{18}$ & 10.65 \\
\hline$v_{18}$ to $v_{1}$ & 10.65 \\
\hline$v_{1}$ to $v_{19}$ & 6.3 \\
\hline$v_{19}$ to $v_{1}$ & 6.3 \\
\hline$v_{1}$ to $v_{20}$ & 18.11 \\
\hline$v_{20}$ to $v_{1}$ & 18.5 \\
\hline$v_{1}$ to $v_{21}$ & 13.51 \\
\hline$v_{21}$ to $v_{1}$ & 12.9 \\
\hline
\end{tabular}


After searching for the shortest path from Semarang State University to other public places, the next step is to determine the fares based on distance and terrain difficulty using the Mamdani FIS. Firstly, we present the data of of terrain difficulties and distances from GoogleMaps and the data of Fares from an ojek online system in Table 5.

Table 5. The data of Terrain Difficulties, Distances, and the Fares of the actual system.

\begin{tabular}{|l|c|c|c|}
\hline Description & $\begin{array}{c}\text { Distance } \\
(\mathrm{km})\end{array}$ & $\begin{array}{c}\text { Terrain } \\
\text { Difficulty }(\mathrm{m})\end{array}$ & Fare (IDR) \\
\hline$v_{1}$ to $v_{2}$ & 11.76 & 348 & 27,048 \\
\hline$v_{2}$ to $v_{1}$ & 9.85 & 348 & 22,655 \\
\hline$v_{1}$ to $v_{3}$ & 11.11 & 348 & 25,553 \\
\hline$v_{3}$ to $v_{1}$ & 12.3 & 348 & 28,290 \\
\hline$v_{1}$ to $v_{4}$ & 11.01 & 348 & 25,323 \\
\hline$v_{4}$ to $v_{1}$ & 10.6 & 348 & 24,380 \\
\hline$v_{1}$ to $v_{5}$ & 13.01 & 348 & 29,923 \\
\hline$v_{5}$ to $v_{1}$ & 12.9 & 348 & 29,670 \\
\hline$v_{1}$ to $v_{6}$ & 5.5 & 300 & 12,650 \\
\hline$v_{6}$ to $v_{1}$ & 5.5 & 300 & 12,650 \\
\hline$v_{1}$ to $v_{7}$ & 9.61 & 348 & 22,103 \\
\hline$v_{7}$ to $v_{1}$ & 9.61 & 348 & 22,103 \\
\hline$v_{1}$ to $v_{8}$ & 14.21 & 348 & 32,683 \\
\hline$v_{8}$ to $v_{1}$ & 14.1 & 348 & 32,430 \\
\hline$v_{1}$ to $v_{9}$ & 6.6 & 300 & 15,180 \\
\hline$v_{9}$ to $v_{1}$ & 6.6 & 300 & 15,180 \\
\hline$v_{1}$ to $v_{10}$ & 10.64 & 348 & 24,472 \\
\hline$v_{10}$ to $v_{1}$ & 10.94 & 348 & 25,162 \\
\hline$v_{1}$ to $v_{11}$ & 13.01 & 348 & 29,923 \\
\hline$v_{11}$ to $v_{1}$ & 13.4 & 348 & 30,820 \\
\hline$v_{1}$ to $v_{12}$ & 10.3 & 300 & 23,690 \\
\hline$v_{12}$ to $v_{1}$ & 10.3 & 300 & 23,690 \\
\hline$v_{1}$ to $v_{13}$ & 11.94 & 348 & 27,462 \\
\hline$v_{13}$ to $v_{1}$ & 12.24 & 348 & 28,152 \\
\hline$v_{1}$ to $v_{14}$ & 15.65 & 300 & 35,995 \\
\hline$v_{14}$ to $v_{1}$ & 15.65 & 300 & 35,995 \\
\hline$v_{1}$ to $v_{15}$ & 4.46 & 348 & 10,258 \\
\hline$v_{15}$ to $v_{1}$ & 4.46 & 348 & 10,258 \\
\hline$v_{1}$ to $v_{16}$ & 0.35 & 348 & 7,000 \\
\hline$v_{16}$ to $v_{1}$ & 0.35 & 348 & 7.000 \\
\hline$v_{1}$ to $v_{17}$ & 8.41 & 348 & 19,343 \\
\hline$v_{17}$ to $v_{1}$ & 8.41 & 348 & 19,343 \\
\hline$v_{1}$ to $v_{18}$ & 10.65 & 348 & 24,495 \\
\hline$v_{18}$ to $v_{1}$ & 10.65 & 348 & 24,495 \\
\hline$v_{1}$ to $v_{19}$ & 6.3 & 300 & 14,490 \\
\hline$v_{19}$ to $v_{1}$ & 6.3 & 300 & 14,490 \\
\hline$v_{1}$ to $v_{20}$ & 18.11 & 348 & 41,653 \\
\hline$v_{20}$ to $v_{1}$ & 18.5 & 348 & 42,550 \\
\hline$v_{1}$ to $v_{21}$ & 13.51 & 348 & 31,073 \\
\hline$v_{21}$ to $v_{1}$ & 12.9 & 348 & 29,670 \\
\hline
\end{tabular}

The fuzzy sets of each variable are defined as in Table 6.

Table 6. Universal Set of Each Variable

\begin{tabular}{|c|l|r|}
\hline Variables & Fuzzy Sets & Universal Sets \\
\hline \multirow{3}{*}{ Distance } & Short & {$[0.35$ 18.5] } \\
\cline { 2 - 3 } & Medium & {$[0.35$ 18.5] } \\
\cline { 2 - 3 } Terrain Difficulty & Long & {$[0.3518 .5]$} \\
\cline { 2 - 3 } & Low & {$[0348]$} \\
\cline { 2 - 3 } & Medium & {$[0348]$} \\
\hline \multirow{3}{*}{ Fare } & High & {$[0348]$} \\
\cline { 2 - 3 } & Low & {$[700042550]$} \\
\cline { 2 - 3 } & Medium & {$[700042550]$} \\
\cline { 2 - 3 } & High & {$[700042550]$} \\
\hline
\end{tabular}

Whereas, the domain of each membership function is given in Table 7.

Table 7. Domains of Membership Functions of Fuzzy Sets

\begin{tabular}{|c|c|c|}
\hline Variables & Fuzzy Sets & Domains \\
\hline \multirow{3}{*}{ Distance } & Short & {$[0.35$ 8.4] } \\
\cline { 2 - 3 } & Medium & {$[5.413 .45]$} \\
\cline { 2 - 3 } & Long & {$[10.4518 .5]$} \\
\hline \multirow{3}{*}{ Terrain Difficulty } & Low & {$[0118]$} \\
\cline { 2 - 3 } & Medium & {$[115233]$} \\
\cline { 2 - 3 } & High & {$[230348]$} \\
\hline \multirow{3}{*}{ Fare } & Low & {$[700020850]$} \\
\cline { 2 - 3 } & Medium & {$[1785031700]$} \\
\cline { 2 - 3 } & High & {$[2870042550]$} \\
\hline
\end{tabular}

The process of Mamdani FIS is described below.

\section{Fuzzyfication}

Distance Variable:

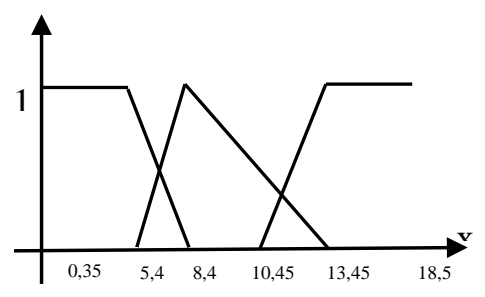

$\mu_{\text {short }}(x)=\left\{\begin{array}{c}1 ; x \leq 5,4 \\ \frac{8.4-x}{8.4-5.4} ; 5.4<x<8.4 \\ 0 ; x \geq 8.4\end{array}\right.$ 


$$
\begin{gathered}
\mu_{\text {medium }}(x)=\left\{\begin{array}{c}
0 ; x \leq 5.4 \text { or } x \geq 13.45 \\
\frac{x-5.4}{8.4-5.4} ; 5.4 \leq x \leq 8.4 \\
\frac{13.45-x}{13.45-8.4} ; 8.4 \leq x \leq 13.45
\end{array}\right. \\
\mu_{\text {long }}(x)=\left\{\begin{array}{c}
0 ; x \leq 10.45 \\
\frac{x-10.45}{13.45-10.45} ; 10.45 \leq x \leq 13.45 \\
1 ; x \geq 13.45
\end{array}\right.
\end{gathered}
$$

Terrain Difficulty Variable:

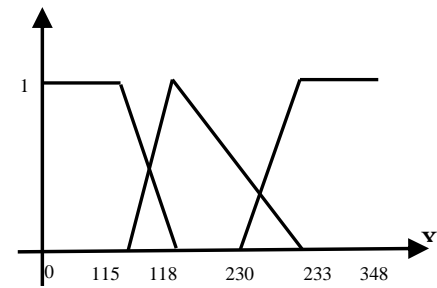

$\mu_{\text {low }}(x)=\left\{\begin{array}{c}1 ; x \leq 115 \\ \frac{118-x}{118-115} ; 115<x<118 \\ 0 ; x \geq 118\end{array}\right.$

$\mu_{\text {medium }}(x)=\left\{\begin{array}{c}0 ; x \leq 115 \text { or } x \geq 233 \\ \frac{x-115}{118-115} ; 115 \leq x \leq 118 \\ \frac{233-x}{233-118} ; 118 \leq x \leq 233\end{array}\right.$

$\mu_{\text {high }}(x)=\left\{\begin{array}{c}0 ; x \leq 230 \\ \frac{x-230}{233-230} ; 230 \leq x \leq 233 \\ 1 ; x \geq 348\end{array}\right.$

Fare Variable:
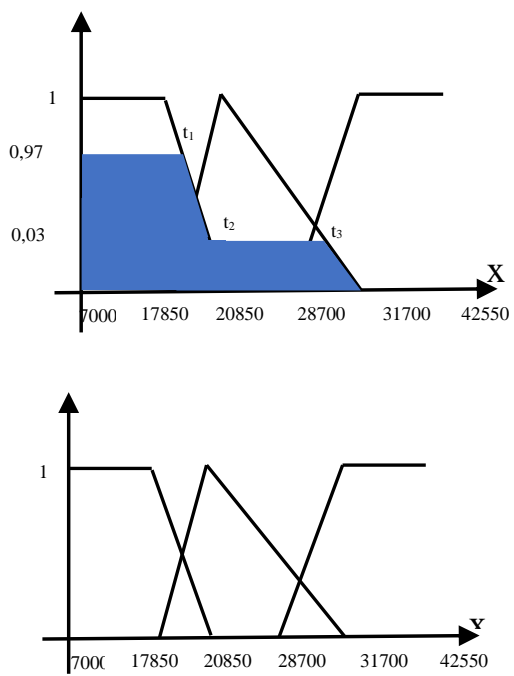

$\mu_{\text {low }}(x)=\left\{\begin{array}{c}1 ; x \leq 17850 \\ \frac{20850-x}{20850-17850} ; 17850<x<20850 \\ 0 ; x \leq 7000 \text { and } x \geq 20850\end{array}\right.$

$$
\begin{aligned}
& \mu_{\text {medium }}(x) \\
& =\left\{\begin{array}{c}
0 ; x \leq 17850 \text { or } x \geq 31700 \\
\frac{x-17850}{20850-17850} ; 17850 \leq x \leq 20850 \\
\frac{31700-x}{31700-20850} ; 20850 \leq x \leq 31700
\end{array}\right. \\
& \mu_{\text {high }}(x)=\left\{\begin{array}{c}
0 ; x \leq 28700 \\
\frac{x-28700}{31700-28700} ; 28700 \leq x \leq 31700 \\
1 ; x \geq 31700
\end{array}\right.
\end{aligned}
$$

\section{Formation of fuzzy sets}

Choose one of the data in Table 5 with a distance of 5.5 $\mathrm{KM}$ and a terrain difficulty of $300 \mathrm{~m}$

$$
\begin{gathered}
\mu_{\text {short }}(5,5)=\frac{8.4-5.5}{8.4-5.4}=0.97 \\
\mu_{\text {medium }}(5,5)=\frac{5.5-5.4}{8.4-5.4}=0.03 \\
\mu_{\text {high }}(300)=1
\end{gathered}
$$

3. Inference

[R1]: If the distance is short and the difficulty of terrain is high then the fare is low.

$\mu R 1=\mu_{\text {short }}(x) \cap \mu_{\text {high }}(x)=\mu_{\text {short }}(5.5) \cap$

$\mu_{\text {high }}(300)=\min (0.97 ; 1)=0.97$

$[R 2]$ If the distance is medium and the difficulty of terrain is high then the fare is medium.

$$
\begin{aligned}
\mu R 2=\mu_{\text {medium }}(x) & \cap \mu_{\text {high }}(x) \\
= & \mu_{\text {medium }}(5.5) \cap \mu_{\text {high }}(300) \\
& =\min (0.03 ; 1)=0.03 .
\end{aligned}
$$

The value of $t_{1}$

$$
\begin{aligned}
& \frac{20850-t_{1}}{20850-17850}=0.97 \\
& 20850-t_{1}=2910 \\
& t_{1}=17940
\end{aligned}
$$

The value of $t_{2}$

$$
\begin{aligned}
& \frac{20850-t_{2}}{20850-17850}=0.03 \\
& 20850-t_{2}=90 \\
& t_{2}=20760
\end{aligned}
$$

The value of $t_{3}$

$$
\begin{aligned}
& \frac{31700-t_{3}}{31700-20850}=0.03 \\
& 31700-t_{3}=325.5
\end{aligned}
$$


$t_{3}=31374.5$

We get

$$
\mu_{\text {fare }}(z)=\left\{\begin{array}{c}
0.97 ; 7000 \leq z \leq 17940 \\
\frac{20850-z}{20850-17850} ; 17940 \leq x \leq 20760 \\
0.03 ; 20760 \leq z \leq 31374.5 \\
\frac{31700-z}{31700-20850} ; 31374.5 \leq z \leq 31700
\end{array}\right.
$$

4. Defuzzification

$$
\begin{aligned}
& \left.M_{1}=\int_{7000}^{17940}(0.97) z d z=0.485 z^{2}\right]_{7000}^{17940} \\
& =156094146-23765000=132329146 \\
& M_{2}=\int_{17940}^{20760}\left(\frac{20850-z}{3000}\right) z d z \\
& \left.=3.475 z^{2}-\frac{1}{9000} z^{3}\right]_{17940}^{20760} \\
& =503525496-476864934=26660562 \\
& \left.M_{3}=\int_{20760}^{31374.5}(0.03) z d z=0.015 z^{2}\right]_{20760}^{31374.5} \\
& =14765388.8-6464664=8300724.8 \\
& M_{4}=\int_{31374,5}^{31700}\left(\frac{31700-z}{10850}\right) z d z \\
& \left.=1.46 z^{2}-\frac{1}{32550} z^{3}\right]_{31374.5}^{31700} \\
& =488354086-488490767=136681 \\
& A_{1}=10940 \times 0.97=10611.8 \\
& A_{2}=\frac{(0.03+0.97) \times 2820}{2}=1410 \\
& A_{3}=10614.5 \times 0.03=318.435 \\
& A_{4}=\frac{0.03 \times 325.5}{2}=4.8825
\end{aligned}
$$

Thus,

$$
Z^{*}
$$

$$
\begin{aligned}
& =\frac{132329146+26660562+8300724,8+136681}{10611.8+1410+318.435+4.8825} \\
& =\frac{167427114}{12345.12}=13562.21
\end{aligned}
$$

The manual calculations with the input of distance $5.5 \mathrm{~km}$ and terrain difficulty of $300 \mathrm{~m}$ produce the fare of 13,562 IDR. The calculations of the fares using Matlab Mamdani FIS toolbox are summarized in Table 8.

In Table 9, we present the comparison between the fares obtained in this research and the fares from Gojek.
Table 8. The Fares obtained from Mamdani FIS using Matlab

\begin{tabular}{|l|c|c|c|}
\hline Description & Distance & Terrain & Fare(IDR) \\
\hline$v_{1}$ to $v_{2}$ & 11.76 & 348 & 31,400 \\
\hline$v_{2}$ to $v_{1}$ & 9.85 & 348 & 23,600 \\
\hline$v_{1}$ to $v_{3}$ & 11.11 & 348 & 28,400 \\
\hline$v_{3}$ to $v_{1}$ & 12.3 & 348 & 33,200 \\
\hline$v_{1}$ to $v_{4}$ & 11.01 & 348 & 27,800 \\
\hline$v_{4}$ to $v_{1}$ & 10.6 & 348 & 25,000 \\
\hline$v_{1}$ to $v_{5}$ & 13.01 & 348 & 35,300 \\
\hline$v_{5}$ to $v_{1}$ & 12.9 & 348 & 35,000 \\
\hline$v_{1}$ to $v_{6}$ & 5.5 & 300 & 13,500 \\
\hline$v_{6}$ to $v_{1}$ & 5.5 & 300 & 13,500 \\
\hline$v_{1}$ to $v_{7}$ & 9.61 & 348 & 23,600 \\
\hline$v_{7}$ to $v_{1}$ & 9.61 & 348 & 23,600 \\
\hline$v_{1}$ to $v_{8}$ & 14.21 & 348 & 36,400 \\
\hline$v_{8}$ to $v_{1}$ & 14.1 & 348 & 36,400 \\
\hline$v_{1}$ to $v_{9}$ & 6.6 & 300 & 17,100 \\
\hline$v_{9}$ to $v_{1}$ & 6.6 & 300 & 17,100 \\
\hline$v_{1}$ to $v_{10}$ & 10.64 & 348 & 25,300 \\
\hline$v_{10}$ to $v_{1}$ & 10.94 & 348 & 27,400 \\
\hline$v_{1}$ to $v_{11}$ & 13.01 & 348 & 35,300 \\
\hline$v_{11}$ to $v_{1}$ & 13.4 & 348 & 36,300 \\
\hline$v_{1}$ to $v_{12}$ & 10.3 & 300 & 23,700 \\
\hline$v_{12}$ to $v_{1}$ & 10.3 & 300 & 23,700 \\
\hline$v_{1}$ to $v_{13}$ & 11.94 & 348 & 32,000 \\
\hline$v_{13}$ to $v_{1}$ & 12.24 & 348 & 33,000 \\
\hline$v_{1}$ to $v_{14}$ & 15.65 & 300 & 36,400 \\
\hline$v_{14}$ to $v_{1}$ & 15.65 & 300 & 36,400 \\
\hline$v_{1}$ to $v_{15}$ & 4.46 & 348 & 13,100 \\
\hline$v_{15}$ to $v_{1}$ & 4.46 & 348 & 13,100 \\
\hline$v_{1}$ to $v_{16}$ & 0.35 & 348 & 13,100 \\
\hline$v_{16}$ to $v_{1}$ & 0.35 & 348 & 13,100 \\
\hline$v_{1}$ to $v_{17}$ & 8.41 & 348 & 23,500 \\
\hline$v_{17}$ to $v_{1}$ & 8.41 & 348 & 23,500 \\
\hline$v_{1}$ to $v_{18}$ & 10.65 & 348 & 25,400 \\
\hline$v_{18}$ to $v_{1}$ & 10.65 & 348 & 25,400 \\
\hline$v_{1}$ to $v_{19}$ & 6.3 & 300 & 16,200 \\
\hline$v_{19}$ to $v_{1}$ & 6.3 & 300 & 16,200 \\
\hline$v_{1}$ to $v_{20}$ & 18.11 & 348 & 36,400 \\
\hline$v_{20}$ to $v_{1}$ & 18.5 & 348 & 36,400 \\
\hline$v_{1}$ to $v_{21}$ & 13.51 & 348 & 36,400 \\
\hline$v_{21}$ to $v_{1}$ & 12.9 & 348 & 35,000 \\
\hline
\end{tabular}


Table 9. Comparison of the Fares produced in this Research and the Fares from Gojek

\begin{tabular}{|c|c|c|}
\hline Description & $\begin{array}{c}\text { Fare Output from } \\
\text { this Research } \\
\text { (IDR) }\end{array} \mid$ & Gojek's Fare (IDR) \\
\hline$v_{1}$ to $v_{2}$ & 31,400 & 26,000 \\
\hline$v_{2}$ to $v_{1}$ & 23,600 & 20,000 \\
\hline$v_{1}$ to $v_{3}$ & 28,400 & 25,000 \\
\hline$v_{3}$ to $v_{1}$ & 33,200 & 27,000 \\
\hline$v_{1}$ to $v_{4}$ & 27,800 & 24,000 \\
\hline$v_{4}$ to $v_{1}$ & 25,000 & 21,000 \\
\hline$v_{1}$ to $v_{5}$ & 35,300 & 28,000 \\
\hline$v_{5}$ to $v_{1}$ & 35,000 & 24,000 \\
\hline$v_{1}$ to $v_{6}$ & 13,500 & 12,000 \\
\hline$v_{6}$ to $v_{1}$ & 13,500 & 12,000 \\
\hline$v_{1}$ to $v_{7}$ & 23,600 & 23,000 \\
\hline$v_{7}$ to $v_{1}$ & 23,600 & 23,000 \\
\hline$v_{1}$ to $v_{8}$ & 36,400 & 29,000 \\
\hline$v_{8}$ to $v_{1}$ & 36,400 & 26,000 \\
\hline$v_{1}$ to $v_{9}$ & 17,100 & 15,000 \\
\hline$v_{9}$ to $v_{1}$ & 17,100 & 15,000 \\
\hline$v_{1}$ to $v_{10}$ & 25,300 & 23,000 \\
\hline$v_{10}$ to $v_{1}$ & 27,400 & 21,000 \\
\hline$v_{1}$ to $v_{11}$ & 35,300 & 28,000 \\
\hline$v_{11}$ to $v_{1}$ & 36,300 & 29,000 \\
\hline$v_{1}$ to $v_{12}$ & 23,700 & 24,000 \\
\hline$v_{12}$ to $v_{1}$ & 23,700 & 24,000 \\
\hline$v_{1}$ to $v_{13}$ & 32,000 & 24,000 \\
\hline$v_{13}$ to $v_{1}$ & 33,000 & 23,000 \\
\hline$v_{1}$ to $v_{14}$ & 36,400 & 33,000 \\
\hline$v_{14}$ to $v_{1}$ & 36,400 & 33,000 \\
\hline$v_{1}$ to $v_{15}$ & 13,100 & 9,000 \\
\hline$v_{15}$ to $v_{1}$ & 13,100 & 9,000 \\
\hline$v_{1}$ to $v_{16}$ & 13,100 & 5,000 \\
\hline$v_{16}$ to $v_{1}$ & 13,100 & 5,000 \\
\hline$v_{1}$ to $v_{17}$ & 23,500 & 19,000 \\
\hline$v_{17}$ to $v_{1}$ & 23,500 & 19,000 \\
\hline$v_{1}$ to $v_{18}$ & 25,400 & 22,000 \\
\hline$v_{18}$ to $v_{1}$ & 25,400 & 22,000 \\
\hline$v_{1}$ to $v_{19}$ & 16,200 & 14,000 \\
\hline$v_{19}$ to $v_{1}$ & 16,200 & 14,000 \\
\hline$v_{1}$ to $v_{20}$ & 36,400 & 40,000 \\
\hline$v_{20}$ to $v_{1}$ & 36,400 & 40,000 \\
\hline$v_{1}$ to $v_{21}$ & 36,400 & 29,000 \\
\hline$v_{21}$ to $v_{1}$ & 35,000 & 26,000 \\
\hline
\end{tabular}

The rates generated by online motorcycle taxis such as Gojek sometimes do not match the distance and the difficulty of terrain that must be taken. Ojek Online drivers sometimes have difficulty when they have to be directed through alternative roads that have difficult terrain such as a fairly steep incline. For example the Gojek fare in Table 9 from point $v_{1}$ to $v_{2}$ is 26,000 IDR, many of the drivers then cancel the order because the total price given is not in accordance with the difficulty of the terrain. So that it is detrimental to both parties, namely between the driver and the customer.
Therefore, the output fares obtained in this research based on the distance and the difficulty of terrain give a better solution. The input of distance of $11.76 \mathrm{~km}$ and the difficulty of terrain of $348 \mathrm{~m}$ (in Table 8 ) give a fare of 31,400 IDR.

Based on Table 9, it can be seen that the fares obtained by Mamdani FIS are a slightly more expensive than the fares from Gojek. Hence, the results in Table 9 are in accordance with the aims expected in this study, i.e., when the distances on two routes are the same but the levels of terrain difficulty are different, the fares will be different.

\section{CONCLUSION}

Based on the results and discussions that have been carried out, it can be concluded that

1. The process to obtain the shortest paths from the initial vertex, i.e., State University of Semarang to some destination points, i.e., several public places in Semarang City are as follows: (i) collecting the data of detination points using a survey via google form, (ii) drawing the graph model of the network of routes using the functions of graph theory in Matlab. The vertices on the graph represent Semarang State University and several public places in Semarang City, while the edges represent the connections between one point to another, and the edge weights represent the distance from one vertex to another, (iii) implementing the Dijkstra Algorithm to determine the shortest paths from Semarang State University to public places in Semarang City and the paths to several public places that have different return directions. The results of the the shortest paths for Ojek Online are presented in Table 8.

2. The height of the field along the shortest path is lied in the interval $[0,348]$. It is expressed as a fuzzy set of low difficulty in the interval $[0,118]$, a fuzzy set of medium difficulty in the interval [115, 233], and is expressed as a fuzzy set of high difficulty at the interval [230, 348]. The data difficulty of the terrain can be seen from the terrain height of each route.

Determination of the fares has been done by Mamdani FIS with the input variables are distance with interval $[0.35,18.5]$ and terrain difficulty with interval $[0,348]$. The output variable, namely fares in the intervals [7000, 42550]. Each variable has a fuzzy set, namely short or low, medium, and high. The rules used in this study are 9 rules and the defuzzification method used is the centroid method. So that the Mamdani FIS give a better fare compared to the existing fares from Gojek. If the distance on the two routes is the same but the level of difficulty of the terrain is different, then the fare is different. 


\section{REFERENCES}

[1] B. Bollobas, Modern Graph Theory, New York: Springer, 2013.

[2] I. Rosyida, Nurhaida, A. Narendra, \& Widodo, Matlab algorithms for traffic light assignment using fuzzy graph, fuzzy chromatic number, and fuzzy inference system. MethodsX, 7, 2020, 101-136. https://doi.org/10.1016/j.mex.2020.101136.

[3] M.Iqbal, K. Zhang, S. Iqbal, \& I. Tariq, A Fast and Reliable Dijkstra Algorithm for Online Shortest Path. International Journal of Computer Science and Engineering, 5(12), 2018, 24-27. https://doi.org/10.14445/23488387/ijcse-v5i12p106

[4] M.S. Yusuf, H. M. Az-zahra, \& D. H. Apriyanti, Implementation of Dijkstra's Algorithm in Finding the Nearest Distance From the User's Location to the Destined Plant Based on Android (Case Study at Purwodadi Botanical Gardens). Jurnal Pengembangan Teknologi Informasi dan Ilmu Komputer, 1, 2017, 1779-1781.

[5] W. E. Y. Retnani, D. Istiadi, \& A. Roqib, Searching for the Nearest Gas Station and Determining the Shortest Distance Using Dijkstra's Algorithm. National Journal of Electrical Engineering, 4(1), 2015, 89-93.

[6] A. M. Ahmed, S. H. Ahmed,\& O. H. Ahmed, Dijkstra algorithm applied: Design and implementation of a framework to find nearest hotels and booking systems in Iraqi. International Conference on Current Research in Computer Science and Information Technology, ICCIT, 2017, 126-132.

\section{https://doi.org/10.1109/CRCSIT.2017.7965546}

[7] T. S. Dermawan, Comparison of Dijkstra dan FloydWarshall Algorithm to Determine the Best Route of Train. IJID (International Journal on Informatics for Development),7(2), 2019, 8, https://doi.org/10.14421/ijid.2018.07202
[8] K. Iqbal, M. A. Khan, S. Abbas, Z. Hasan, \& A. Fatima, Intelligent transportation system (ITS) for smart-cities using Mamdani Fuzzy Inference System.International Journal of Advanced Computer Science and Applications, 9(2), 2018, 94105.https://doi.org/10.14569/IJACSA.2018.090215

[9] K. Yudhistiro, \& H. Pamuntjar, Mamdani Fuzzy Inference System for Decision Support in Determining Village Potential in Malang Regency. Journal High School, 9(01), 2019, 28-38. https://doi.org/10.32664/smatika.v9i01.244

[10] S. Setiawan, Utilization of Fuzzy Inference System in Determining the Extension of the Employment Contract. Informatics for Educators and Professionals, 2(1), 2017, 71-80.

[11] I. Rosyida, T.S.N. Asih, S.B. Waluya, and Sugiyanto, Fuzzy shortest path approach for determining public bus route (case study: route planning for "Trans Bantul Bus" in Yogyakarta, Indonesia). Journal of Discrete Mathematical Sciences and Cryptography 24, 2021, 557-77.

[12] I.K. Budayasa, Graph Theory and Its Applications. Surabaya: Unesa University Press, 2007

[13] Y. Charolina, Decision Support System To Determine The Annual Bonus Using The Mamdani Type Fuzzy Logic Method (Case Study on Employees of PT Sunhope Indonesia in Jakarta). Journal of Information Technology 12, 2016, 42-53.

[14] A. R. Wardani, Y. N. Nasution, \& F. D. T. Amijaya, Application of Fuzzy Logic in Optimizing Palm Oil Production at PT. Waru Kaltim Plantation Using the Mamdani Method. Mulawarman Informatics: Scientific Journal of Computer Science,12(2), 2017,94-103. https://doi.org/10.30872/jim.v12i2.651 